\title{
Exploring the Reliability and Validity of the TechU-Q to Evaluate Device and Purpose Specific Screen Use in Preschool Children and Parents
}

\author{
Erin K. Howie $\mathbb{D}^{1} \cdot$ Shelley McNally ${ }^{1} \cdot$ Leon M. Straker ${ }^{2}$ \\ Published online: 5 August 2020 \\ (c) Springer Science+Business Media, LLC, part of Springer Nature 2020
}

\begin{abstract}
Young children are increasingly using mobile technology, with potential for positive and negative developmental consequences. Parents are responsible to guide children in their use of technology based on recommendations and guidelines. Guidelines for screen use in young children have been based on little empirical information on contemporary screen use. This study surveyed parents of young children $(n=96$, mean child age 3.0, SD 1.0 years) from three settings (Australia, United States) to test the reliability and validity of a new tool to capture richer data on technology use within a techno-microsystem. The TechU-Q demonstrated reasonable test-retest reliability and face and construct validity. Young children averaged more than $60 \mathrm{~min}$ per day of total technology use, mostly using TV, tablet computers, and mobile phones. The primary purposes for child use were educational and watching videos. Parental attitudes towards technology and parent use were associated with their child's use. Future guidelines should utilize detailed descriptions of technology use by device and purpose to provide more relevant advice on technology use for young children.
\end{abstract}

Keywords Technology $\cdot$ Screens $\cdot$ Sedentary $\cdot$ Young child $\cdot$ Quantitative

\section{Highlights}

- The TechU-Q was found to be reliable and valid for assessing young children's and parents' technology use.

- Child technology use was associated with parent technology use.

- Parents had generally neutral attitudes towards young children's technology use, with primary concerns related to technology use decreasing physical activity and increasing sedentary time.

Governments and national agencies, including the American Academy of Pediatrics, the Canadian Paediatric Society and the Australian Department of Health have issued public health guidelines for screen use by young children (Canadian Society for Exercise Physiology 2017; Council on Communications and Media American Academy of Pediatrics 2016; Department of Health 2017), while an understanding of contemporary screen use by young children and its impacts lags behind. These guidelines are

Erin K. Howie

ekhowie@uark.edu

University of Arkansas, Fayetteville, AR 72701, USA

2 Curtin University, Perth, WA, Australia created to help parents and families navigate technology use practices of their children.

Previous guidelines have been revised due to the changing nature of screens in families (Przybylski and Weinstein 2017), childcare, and educational needs (Commonwealth of Australia 2009), including the increasing availability of mobile touch screen devices (MTSD) such as smartphones and tablet computers. In 2017, adult smartphone ownership in Australia was at 88\% (Drumm et al. 2017), and in the US in 2018, adult smartphone ownership was at 95\% (Pew Research Center 2018). Smartphone use is becoming ubiquitous with a recent Australian study reporting $70 \%$ of adults use their phones during mealtimes with family and friends (Drumm et al. 2017).

Increasingly, MTSD are also being used by children, even young children. In 2017 children in the USA under the age of 8 were reported to spend close to an hour per day 
using a MTSD (Howard 2017) and in $201475 \%$ of 4-year olds owned their own mobile device (Kabali et al. 2015). A study of 3-5 year-olds in the USA published in 2018 found parents reported more than $3 \mathrm{~h}$ of mobile device use by their children (Beyens and Nathanson 2018). Parents report that there are large differences in weekday and weekend screen use and by device due to differences in schedules and parental regulations (Solomon-Moore et al. 2018). There have been limited endeavors to validate measures of screen use (Saunders and Vallance 2017). In order to create and implement applicable screen use guidelines, policymakers should have an understanding of the complex screen use behavior of young children and their families.

Anecdotal evidence suggests that parents are providing tablets and smartphones for their young children for a mix of educational and recreational use. Observations of young children suggest they are drawn to the fun aspects of tablet and smartphone use, with the intuitive gesture-based touch screen interface enabling even very young children to be independent in playing games, watching videos, etc. Research has found that children from ages 2 to 4 in India were able to scribble and draw using a smartphone app (Yadav and Chakraborty 2017). They are also being given to children by parents as a way to calm children (Radesky et al. 2016). Further, anecdotal evidence shows mass media are encouraging parents to give children an advantage at school by providing them with a tablet and educational apps. Early childhood educators are also being encouraged to teach young children to be competent users of technology (Commonwealth of Australia 2009; Paciga and Donohue 2017). However, little empirical evidence on the purpose of use of MTSD by young children currently exists in the literature.

The recent screen use guidelines have been prompted by a growing concern about the effects of MTSD use on physical and mental health, well-being and general development including musculoskeletal discomfort (Toh et al. 2017), family interactions (Carlson et al. 2017), and learning (Domingo and Gargante 2016). Whilst much of this interest has been focused on adults, adolescents and older children (Vernon et al. 2018), there are now growing concerns from parents and professionals for young children's physical, social and cognitive development (Anderson and Subrahmanyam 2017; Straker and Howie 2016; Zabatiero et al. 2018). Laboratory evidence suggests use of tablet computers may have physical effects on young children's activity and posture (Howie et al. 2017), and tablet use by preschoolers has been associated with sleep disturbances (Nathanson and Beyens 2018). Parents are reported to have both positive and negative attitudes about young children using screens (Kostyrka-Allchorne et al. 2017; McCloskey et al. 2018; Zabatiero et al. 2018). Positive ideas relate to interactive child games potentially encouraging positive parent-child interactions (Skaug et al. 2017) and potentially enhancing learning (Radesky et al. 2015) but increased screen use may have negative effects on social interactions (Hinkley et al. 2018). Similarly early childhood educators have both positive and negative attitudes about screen use by young children, recognizing the potential to enhance learning and the potential for harm (Zabatiero et al. 2018). Evidence from earlier generations of technology suggest that it is not just the total time of use that is important, but that different devices may result in different effects (Straker et al. 2008) and that the effect of technology use can depend on the purpose of use (Council on Communications and Media American Academy of Pediatrics 2016; Radesky et al. 2015).

This growing use and potential consequences for children's social, emotional, mental, and physical development have resulted in the recent updates to screen technology use recommendations from national health organizations (Canadian Society for Exercise Physiology 2017; Council on Communications and Media American Academy of Pediatrics 2016; Department of Health 2017). However, these authorities have had to meet the real world need for guidance with very limited evidence regarding the current patterns and purposes of use by children and their parents and also very limited evidence on the impacts of this MTSD use. Research on the techno-microsystem has found that internet use of specific types, within specific contexts was associated with children's social, emotional, physical and cognitive development (Johnson 2010). The techno-microsystem is an ecological model that highlights the reciprocal interactions of child characteristics, technologies, and the environment. It specifies multiple uses of technologies including communication, information and recreation across multiple settings such as school, home and community. To better understand the developmental implications of technology use in young children, it is important to better understand the use and context, including family use, that contribute.

An important step to better understand the implications of MTSD use, and thus provide evidence to inform health and education guidelines (Straker et al. 2018), is the development of a reliable, valid, and feasible measure to capture family screen technology use (Saunders and Vallance 2017). Given the potential differential effects of device and purpose of use as proposed by the technomicrosystem (Johnson 2010), exposure assessment needs to be at this detailed level. Currently, to our knowledge, there is no such measure that can be used to assess comprehensive screen technology use including the access, duration, frequency and purpose of use for multiple devices including MTSDs, television, computers, and electronic games.

In summary, to provide better information to families and others supporting families with young children regarding appropriate use of MTSD it is important to understand the contemporary use of these devices within the family 
context, including details on the devices used and the purposes of use. To develop such an understanding, a reliable and valid tool is required to capture details of screen use in families. Therefore, the objectives of the study were:

1. To evaluate the reliability and face, content and construct validity of the Technology Use Questionnaire Parent report version (TechU-Q(parent)) and Technology Use Questionnaire Adult version (TechU$\mathrm{Q}$ (adult)). It was hypothesised that the TechU-Q would have face and content validity confirmed by users and an expert panel. In relation to construct validity, it was hypothesised that parents' technology use would be higher among those with sedentary occupations, children's outdoor play would be associated with lower technology use, and more positive parent perceptions would be associated with higher technology use in their children.

2. To provide a detailed description of technology use among young children and their parents including by device and purpose of use. It was hypothesised that the technology use of young children would be positively related to the technology use of parents.

\section{Methods}

\section{Participants}

The convenience sample consisted of parents of young children attending participating childcare settings between January 2016 and January 2018. Three settings were selected to represent a range of factors potentially contributing to children's technology use and parental understanding of questionnaires. Settings: (1) a private not-forprofit childcare organization catering for predominantly low SES families in metropolitan Perth, Western Australia, (2) a university childcare center in metropolitan Perth and, (3) a university childcare center in a town in central United States. Parents completing the survey had to be English speaking, 18 years or older, and be a primary caregiver to a child from 0 to 5 years of age. Participating parents completed the TechU-Q(adult) for their own technology use and the TechU-Q(parent) for the technology use of their child (ren). The study was approved by Curtin University and University of Arkansas Institutional Review Boards.

\section{Procedures}

Information on the study was distributed to all parents with a child attending the participating childcare settings. The online baseline survey was distributed to all parents through an email link sent by the childcare setting. Informed consent was obtained as the first part of the questionnaire, before entering personal information and beginning the questionnaire content. Hard copy surveys were available as an alternative, upon request. During initial survey completion, parents were asked to provide their email address and a unique name to enable matching to the repeated survey. No complete names or further identifying information were collected.

\section{Measures}

The Technology Use Questionnaire (TechU-Q) was developed utilizing 20 years of experience collecting parent and child reports of technology use (Harris and Straker 2000; Harris et al. 2017) and existing published surveys of child technology use (Hinkley et al. 2012; Houghton et al. 2015). Initial construction of the TechU-Q was conducted through an iterative process involving technology use experts and pilot tests with users. Versions were prepared for parentproxy report of young children's (birth to 5 years) use (TechU-Q parent), children's (8-17 years) self-report (TechU-Q child - see Straker et al. for reliability and validity evaluation details (Straker et al. 2017)) and adult parent self-report (TechU-Q child). The TechU-Q was pilot tested for feasibility in a sample of over 150 parents of young children (Coenen et al. 2015).

TechU-Q includes questions on frequency, duration and purpose of weekday and weekend day use of multiple technology devices (television, computers, tablet computers, mobile phones, and electronic games). For young children, parents were asked to report the amount of time using each device for each purpose: educational activities, social networking, watching videos, playing games, and other general use. Parents were asked about the proportion of their own use of each device for each purpose: occupation, social networking, watching videos, playing games, and other general use. An example question from the parent-proxy questionnaire is "Over a typical Monday to Friday period, on how many days does your child use screen devices?" (drop down menu for number of days) followed by "On each of these weekdays, for about how long does your child use screen devices per day?" (drop down menu from $5 \mathrm{~min}$ to $12 \mathrm{~h}$ or more). Total technology use and device specific use was tabulated by multiplying duration of use by frequency of use for both weekdays and weekend days. The survey was administered using the Qualtrics (Qualtrics, Provo, Utah, USA) platform. The complete online version of the questionnaire is available by request from the authors.

Demographic information including date of birth, gender, postcode, parent education, and occupation were obtained for both the adult and (where relevant) their child (ren) as per prior studies (Straker et al. 2015). 


\section{Reliability}

To provide estimates of test-retest reliability, the same questionnaire was re-distributed directly using the provided email address to participants 2 weeks following the date of the initial baseline completion in settings 1 and 2 only.

\section{Face validity}

Face validity was explored with parents. Qualitative methods were used to assess the face validity of the TechU-Q (parent) and TechU-Q(adult) among end-users. Questionnaire comments were provided and semi-structured interviews were conducted with a convenience sample of parents of young children. The interviewer asked prompted questions on feasibility, comprehension, comprehensiveness and accuracy. Additionally, the interviewer checked comprehension by asking the participants to elaborate on answers to the questionnaire. Questions were asked separately for TechU-Q(adult) and TechU-Q(parent). The interviewer completed detailed field notes during the interviews.

\section{Content validity}

To further establish the content validity, 10 experts in research of technology use by children, measurement and activity and task behaviors, and childcare professionals were sent the questionnaire along with a brief description of the intended constructs to measure. Experts were asked to respond to the following questions as well as to provide any additional comments: (1) Were the exposure categories appropriate for technology use by young children, adolescents and adults to capture meaningful duration and frequency of use and (2) Were any common technology devices not included?

\section{Construct validity}

Construct validity was explored through associations with parental use, parental perceptions and children's physical activity. Additional questions on perceived risk, benefits and concerns of parents regarding technology use were collected. These questions assessed parents' perceptions of educational, social, physical and overall risk of MTSD use. It was hypothesized that more positive parent perceptions would be associated with higher technology use in their children. Parents were also asked about their child's level of outdoor play as an indicator of overall physical activity level, as it was hypothesized that outdoor play would be negatively associated with technology use. Total outdoor play, weekly outdoor play, and weekend outdoor play during both warmer and cooler months was calculated. The outdoor play questions have been related to objectively measured physical activity and total weekly outdoor play with a one week intraclass correlation (ICC) of 0.41 in children reported (Cleland et al. 2008).

\section{Analysis}

To assess the test-retest reliability, intraclass correlations (ICC) were calculated for total technology use volume for young children and adults separately, and separately for each device. ICC's $\geq 0.9$ were considered excellent, between 0.75 and 0.9 was good, between 0.5 and 0.75 was moderate and $<0.5$ was poor (Koo and Li 2016).

\section{Face Validity}

Face validity was assessed by analysis of the interviews with parents.

\section{Content Validity}

Content validity was assessed by analysis of expert review comments.

\section{Construct Validity}

Construct validity was assessed using Cronbach's alpha, principal components analysis and correlations with hypothesized convergent and divergent constructs. Cronbach's alpha was calculated on the volume of use (product of duration of use of each device and frequency of use) separately for children and parent technology use, standardized as rank order questions to determine if the questions for multiple devices are measuring a single construct. It was hypothesised that the TechU-Q would have low internal consistency, thus providing evidence that multiple device questions need to be asked. A principal components analysis was conducted on the frequency-duration products, separately for children and parents, to further assess the construct differences between devices. Eigen values, factor loadings, variance explained and conceptual interpretation were used to determine the number of factors retained. For children, spearman correlations were determined between children's technology use and parent attitudes towards technology. It was hypothesized that parents with higher perceived risks and lower perceived benefits of technology use would report less use by their children. Spearman correlations were also determined between children's technology use and total weekly outdoor play. It was hypothesized that children with lower levels of outdoor play would have higher levels of technology use. For adults, overall technology use was compared by occupation type using KrusakWallis tests. It was hypothesised that adults with an office 
Table 1 Characteristics of participating parents and their children, Mean (SD) or \%
Table 2 Test-retest reliability (ICC $(95 \% \mathrm{CI})$ ) for parent report of child technology use and own use on weekdays, weekend days and total week (Settings $1 \&$ 2 only)

\begin{tabular}{|c|c|c|c|c|}
\hline & $\begin{array}{l}\text { Total } \\
(n=96)\end{array}$ & $\begin{array}{l}\text { Setting 1 } \\
(n=31)\end{array}$ & $\begin{array}{l}\text { Setting } 2 \\
(n=48)\end{array}$ & $\begin{array}{l}\text { Setting } 3 \\
(n=17)\end{array}$ \\
\hline Child gender ( $\%$ female) & $51.5 \%$ & $46.7 \%$ & $60.4 \%$ & $35.3 \%$ \\
\hline Child age (years) & $3.0(1.1)$ & $3.2(1.1)$ & $2.7(1.1)$ & $3.5(0.8)$ \\
\hline Siblings ( $\%$ with at least one sibling) & $55.2 \%$ & $61.3 \%$ & $47.9 \%$ & $64.7 \%$ \\
\hline $\begin{array}{l}\text { Child outdoor time (mean (SD) } \mathrm{min} / \\
\text { day) }\end{array}$ & $82.2(46.6)$ & $91.2(42.4)$ & $81.5(48.1)$ & $67.8(48.1)$ \\
\hline Parent gender (female) & $88.5 \%$ & $93.6 \%$ & $87.5 \%$ & $82.4 \%$ \\
\hline Parent age (years) & $36.9(5.0)$ & $37.9(4.8)$ & $35.8(5.3)$ & $37.9(4.3)$ \\
\hline $\begin{array}{l}\text { Parent education level ( } \% \\
\text { postgraduate degree ie Master's or } \\
\text { Doctorate) }\end{array}$ & $47.9 \%$ & $38.7 \%$ & $45.8 \%$ & $70.6 \%$ \\
\hline Parent occupation (\% sedentary job) & $78.1 \%$ & $67.7 \%$ & $79.2 \%$ & $94.1 \%$ \\
\hline
\end{tabular}

\begin{tabular}{lllllll}
\hline & $n$ & Weekday & $n$ & Weekend & $n$ & Total \\
\hline Child & & & & & & \\
TV & 27 & $0.58(0.27,0.78)$ & 24 & $0.64(0.33,0.82)$ & 24 & $0.72(0.44,0.87)$ \\
Desktop & 24 & $0.91(0.80,0.96)$ & 24 & $0.96(0.91,0.98)$ & 24 & $0.92(0.82,0.96)$ \\
Laptop & 27 & $0.20(-0.21,0.54)$ & 25 & $0.35(-0.05,0.65)$ & 25 & $0.25(-0.16,0.59)$ \\
Tablet & 24 & $0.50(0.12,0.75)$ & 24 & $0.93(0.85,0.97)$ & 24 & $0.75(0.50,0.88)$ \\
Mobile & 26 & $0.92(0.83,0.96)$ & 23 & $0.88(0.73,0.95)$ & 23 & $0.90(0.79,0.96)$ \\
Total tech & 25 & $0.70(0.42,0.86)$ & 24 & $0.70(0.42,0.86)$ & 25 & $0.71(0.44,0.86)$ \\
Parent & & & & & & \\
TV & 25 & $0.43(0.05,0.70)$ & 24 & $0.85(0.65,0.93)$ & 24 & $0.58(0.24,0.79)$ \\
Desktop & 24 & $0.64(0.33,0.82)$ & 22 & $0.49(0.08,0.75)$ & 22 & $0.64(0.32,0.83)$ \\
Laptop & 24 & $0.89(0.76,0.95)$ & 24 & $0.78(0.55,0.90)$ & 24 & $0.91(0.79,0.96)$ \\
Tablet & 24 & $0.39(-0.01,0.68)$ & 24 & $0.65(0.34,0.83)$ & 24 & $0.42(0.03,0.70)$ \\
Mobile & 24 & $0.43(0.05,0.71)$ & 24 & $0.89(0.76,0.95)$ & 24 & $0.59(0.25,0.80)$ \\
Total tech & 25 & $0.62(0.30,0.81)$ & 23 & $0.79(0.57,0.91)$ & 25 & $0.66(0.36,0.83)$ \\
\hline & & & & &
\end{tabular}

job would have higher computer use compared to physical labor occupations.

\section{Description of Technology Use in Children and Parents}

Descriptive statistics were calculated on the overall use, device-specific use, and purpose-specific use for both young children and adults and for parental attitudes of technology use. Means and standard deviations are presented in the text, however the same pattern existed across devices when medians and 25th-75th intervals were examined. Technology use distribution was found to be non-normal, thus appropriate non-parametric tests were used. Findings were compared across the three settings using Kruskal-Wallis tests. Spearman correlations were used to test the associations between child technology use and parent technology use. Due to the nested structure of the data within settings, data was group-mean centered to account for effect of setting (Meinck and Rodriguez 2013).

\section{Results}

Table 1 shows the characteristics of the participants $(n=96$ reporting on total technology use, mean age $=3.0$ years, range 5.5-64.3 months) at the three settings. As expected, parents in setting 1 had lower educational achievement, less sedentary work and more children.

\section{Test-retest Reliability}

The test-retest reliability of parent-reported child technology use ranged from an ICC of 0.20 for laptop use on weekdays to 0.96 desktop use on weekends, as seen in Table 2. Fifteen of the 18 ICCs were moderate to excellent. ICCs could not be calculated for electronic game device use due to minimal reports of use. Test-retest reliability of parent self-report of technology ranged from and ICC of 0.39 for tablet use on weekdays to 0.91 for total laptop use. Thirteen of the 18 ICCs were moderate to excellent, again excluding electronic game use due to low numbers. 
Table 3 Factor loadings from principal components analysis for daily technology use by children and parents (only loadings greater than 0.3 are shown)

\begin{tabular}{|c|c|c|c|c|c|}
\hline & \multicolumn{3}{|l|}{ Children } & \multicolumn{2}{|l|}{ Parents } \\
\hline & Component 1 & Component 2 & Component 3 & Component 1 & Component 2 \\
\hline $\mathrm{TV}$ & & & 0.96 & & 0.60 \\
\hline Desktop & 0.45 & & & & 0.40 \\
\hline Laptop & 0.42 & & & & 0.37 \\
\hline Tablet & & 0.83 & & & 0.41 \\
\hline Mobile & & 0.50 & & & 0.42 \\
\hline Handheld & 0.47 & & & 0.55 & \\
\hline Console & 0.42 & & & 0.55 & \\
\hline AVG & 0.47 & & & 0.55 & \\
\hline
\end{tabular}

Rotated (varimax) factor loadings; $A V G$ active video games

\section{Face Validity}

Parents found the questions appropriate and no major changes were suggested based on parent feedback.

\section{Content Validity}

Experts commented on the content validity and made suggestions to wording and question structure. All the comments of the experts were summarized, reviewed and survey questions were modified prior to distributing survey through childcare centers based on substantial and consensus comments. Overall, experts agreed with the measured constructs and questions. No major changes were suggested based on expert feedback.

\section{Construct Validity}

Cronbach's alpha was 0.26 for children suggesting low consistency between devices. Principal components analysis suggested three principal components consisting of (1) TV, (2) tablet and mobile, and (3) desktop, laptop and electronic games, as seen in Table 3. Parent attitudes to technology use were typically associated with their children's technology use, with negative attitudes associated with less use and vice versa. Children's technology use was not associated with outdoor play time (total technology rho $=0.16, p=0.147$; TV $r=0.20, p=0.074$; tablet $r=$ $-0.08, p=0.505$; mobile $r=-0.07, p=0.550$ ).

Cronbach's alpha was 0.80 for parents suggesting high consistency between devices. In the principal components analysis all items loaded on two principal components: (1) TV, desktop, laptop, tablet, mobile, and (2) electronic games. Parent weekday total technology use was significantly greater in those with sedentary jobs $(\mathrm{M}=394.8$, $\mathrm{SD}=207.4$ ) minutes per day $p=0.015$ versus those with standing $(\mathrm{M}=215.0, \mathrm{SD}=197.3)$ and physical labor jobs $(\mathrm{M}=265.7, \mathrm{SD}=281.1)$. Use of $\mathrm{TV}$, desktop, laptop, tablet and mobile did not differ between occupational groups $(p>0.05)$.

\section{Description of Technology Use in Children and Parents}

Technology use by young children was dominated by TV on both weekdays $(\mathrm{M}=53.6 \mathrm{~min}$ per day, $\mathrm{SD}=86.6)$ and weekend days $(\mathrm{M}=74.3, \mathrm{SD}=72.8)$, with tablet and mobile used less as seen in Table 4. There were no differences in children's technology use on weekdays between settings. On weekends, there were differences between settings in children's TV use $(p=0.018)$, tablet use ( $p=$ $0.040)$, and total technology use $(p=0.044)$ with higher reported TV and total technology use for children in Setting 3 and lower tablet use in Setting 1. Of children less than 2 years of age, 7 out of 22 (32\%) were reported to have zero technology use. Of children 2 years of age or older, $59 \%$ were reported to accumulate more than $60 \mathrm{~min}$ of technology use per day. Both educational and videos were the dominant purpose of use on both weekdays and weekend days for tablets and mobiles and a comparison of purposes for tablets and mobiles can be seen in Fig. 1.

In contrast, for parents, desktop computers dominated use on weekdays $(\mathrm{M}=234.2, \mathrm{SD}=221.4 \mathrm{~min}$ per day), with substantial use of TV, laptop, mobile and tablets. On weekends, mobile phone $(\mathrm{M}=150.1, \mathrm{SD}=186.7)$ and $\mathrm{TV}(\mathrm{M}=$ $133.7, \mathrm{SD}=125.0$ ) dominated for parents. Social purposes dominated for parents' use of tablets and mobiles, with substantial use for work and general use as seen in Fig. 1.

Parents reported diverse attitudes to technology use by their children with a range from strongly agree to strongly disagree for 9 out of 11 items as seen in Fig. 2 and complete results compared between settings. Parents reported the highest agreement (1-5 scale with 1 being strongly disagree and 5 strongly agree) with the statements "Using mobile technology will increase the amount of time my child spends sitting" $(\mathrm{M}=4.3, \mathrm{SD}=0.8)$ and "Using mobile 
Table 4 Technology use (mean, $\mathrm{SD} \mathrm{min} /$ day) by device on week days and weekend days for young children and their parents
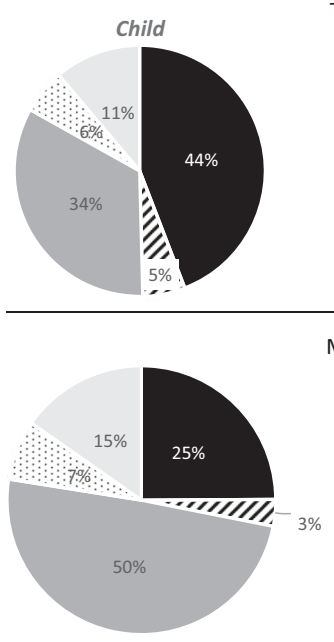

\section{Tablet}

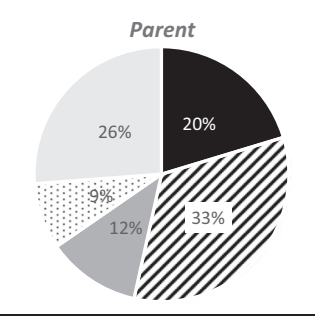

Mobile
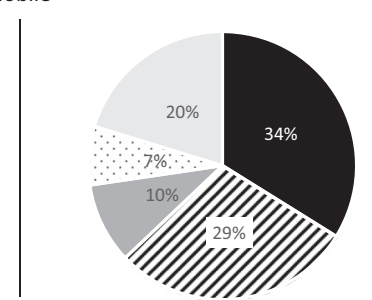

- Educational/Work "Social घ Videos : Games General
Fig. 1 Tablet and mobile weekday use by purpose for children and parents. Educational/Work activities include education activities e.g. reading, number puzzles, alphabet and language games, leaning colors/ shapes and work activities including studying e.g. using Microsoft Office, searching information online, sending work emails; Social activities include social networking/instant messenger NOT for education/work e.g. Skype, Facebook, Instagram, Twitter, WhatsApp, Snapchat, texting, voice calls; General use activities include drawing, taking/editing photos/video, downloading songs, visiting websites, online shopping etc

technology will reduce my child's physical activity" $(\mathrm{M}=$ $4.0, \mathrm{SD}=1.0$ ). Parents agreed with items on mobile technology being good for their child's education $(\mathrm{M}=3.4$, $\mathrm{SD}=0.9)$, harming social skills $(\mathrm{M}=3.2, \quad \mathrm{SD}=1.1)$, making their child at risk to online predators $(\mathrm{M}=3.3$, $\mathrm{SD}=1.1)$, and having overall benefits $(\mathrm{M}=3.2, \mathrm{SD}=0.9)$. Parents disagreed with mobile technology being bad for education ( $\mathrm{M}=2.5, \mathrm{SD}=0.8$ ), being good for their child's education when used in childcare $(\mathrm{M}=2.6, \mathrm{SD}=1.1)$, improving social skills $(\mathrm{M}=2.2, \mathrm{SD}=0.8)$, and being a risk overall $(\mathrm{M}=2.8, \mathrm{SD}=1.0)$. Parents were neutral $(\mathrm{M}$ $=3.0, \mathrm{SD}=1.0)$ on mobile technology causing their child discomfort and pain. There were no differences in attitudes between settings.

Children's TV (total technology use rho $=0.49, p<$ $0.001)$, tablet $(r=0.31, p=0.006)$, and mobile $(r=0.36$, $p=0.002$ ) use was positively associated with their parents' use of each device respectively for total use and weekday use. On weekends, children's use was positively correlated with TV (weekend rho $=0.39, p<0.001)$, mobile $(r=0.25$, $p=0.03)$ and total technology $(r=0.27, p=0.01)$ use by parents. Negative associations were found between child and parent reported use of mobiles on weekends $(r=-0.39, p<0.001)$, and active video games on weekdays $(r=-0.26, p=0.01)$, weekends $(r=-0.24, p=$ $0.03)$ and total $(r=-0.26, p=0.01)$.

\section{Discussion}

The current study aimed to establish face, content and construct validity of the TechU-Q and then to use this measure to explore the device- and purpose-specific use of technology in young children and their parents. The findings support the utility of the TechU-Q with reasonable testretest reliability and evidence of face, content and construct validity. While the reliability for individual devices was sometimes low, such as for laptop use by young children, this may reflect the low frequency and potentially sporadic nature of use. Proxy- or self-report of technology use is less desirable than objective measures for both participant burden and accuracy reasons. However, no valid, low-cost objective method of logging technology device use across the whole day and multiple devices appears to exist. Prior studies have used direct observation (Ciccarelli et al. 2011), 
but this is very research resource intensive and having an observer nearby may alter parent or child behavior. Thus proxy- and self-report remains the only viable option for many studies, and has prior evidence of reasonable validity in comparison to direct observation by a researcher (Ciccarelli et al. 2011). The current study only captured parent informed child use, however the TechU-Q could also be used by childcare staff to report on use during childcare in order to capture the whole exposure of children.

Total daily technology use by young children in this study was over an hour per day with more than half of children 2-5 years participating in more than $1 \mathrm{~h}$ a day of screen use. This is less than in a recent study where children under 5 were reported to watch over 75 min of TV per day and other screens for an additional half hour (Waisman et al. 2018), however it is possible that parents are underreporting children's technology use due to social desirability biases. Thus, it is likely that the majority of young children are not meeting current guidelines of less than $1 \mathrm{~h}$ per day of screen use for children in this age group (Canadian Society for Exercise Physiology 2017; Council on Communications and Media American Academy of Pediatrics 2016; Department of Health 2017). This substantial exposure in young children to screens reinforces the need for a better understanding of potentially important impacts on physical, psychological and social development and the contextual information within the technomicrosystem influencing developmental outcomes (Johnson 2010).

When examining which devices young children are using, TV is still the dominant technology used by these children. As much of the previous research on developmental effects of screens is based on television viewing, those findings are still relevant today (Boulos et al. 2012; Lillard et al. 2015; Marinelli et al. 2014). Television may be a unique exposure compared to other devices as it is primarily passive and also can include a large amount of advertising, e.g. unhealthy foods, targeted towards children (Boulos et al. 2012). Passive viewing of TV has been shown to decrease energy expenditure compared to resting, which may contribute to energy balance dysregulation (Klesges et al. 1993). However, the current findings suggest MTSD use is a significant exposure (approximately half as much time spent as watching TV) justifying the importance of assessing exposure to this new generation of technology.

Both tablets and desktop/laptop computers are being provided to young children for a range of purposes, as reported by parents, with education a common purpose. The high percentage of educational use likely reflects the perceptions of parents that screen use is important for children's education. Whilst parents reported this use to be educational, it is unknown if the content was actually educational. Many apps claim to be educational but actually offer low quality learning opportunities that are solely rote memorization and do not take advantage of the interactive potential of technology (Hirsh-Pasek et al. 2015). Educational apps can and should be further classified in varying quality for educational purposes (Cherner et al. 2014). Future studies should ask about specific educational app usage for app content analysis. For practitioners, future research is needed to determine if young children 2-5 years of age who use "educational apps" are more or less successful when they transition to formal school. Although a high-quality early childhood curriculum currently does not necessarily include screen use, there may be intentionally planned uses for devices that could benefit children. As practitioners prepare children to be successful in formal schooling, understanding and knowing current technology uses has the potential to improve teaching practices.

Parents reporting a high use of screens for passive video viewing in addition to educational purposes may be more worrisome. Earlier research on TV has suggested passive consumption of screens can have detrimental effects on physical (Klesges et al. 1993) and cognitive development (Lillard et al. 2015). However, active engagement with screens may be more likely to lead to aggressive behavior compared to passive consumption (Polman et al. 2008). Social interaction, whether live or by video, may improve the influence of screen use on child development (Roseberry et al. 2014). Together these data suggest that parents need applicable and specific guidance in using MTSD in ways which promote positive outcomes for children whilst minimising the potential for harm.

The results of the current study emphasize the important role parents play in their young children's technology use. Firstly, parent and child use was positively associated for $\mathrm{TV}$, tablet, mobiles and total technology use. The negative associations for active video games and laptop use on weekends was likely due to very small reported use and correlations being driven by outliers. Thus, strategies aimed at altering young children's use may also need to target parent modeling of screen behaviors. Childcare facilities are poised to implement strategies that alter children's use by offering parent education events on the effects of screen use. Secondly, parent attitudes were associated with reported child technology use, with parents having positive attitudes reporting higher use by their child and those with negative attitudes reporting less use by their child. Educating parents on the benefits and risks of technology use in young children may be a useful strategy, as part of a larger strategy, to promote appropriate use of technology in young children.

Overall, parents reported generally neutral attitudes towards young children's technology use, including use in childcare settings, which reflects the previously reported moral dilemma parents have around their children's 
Fig. 2 Parental attitudes towards children's technology use, mean $95 \% \mathrm{CI}$

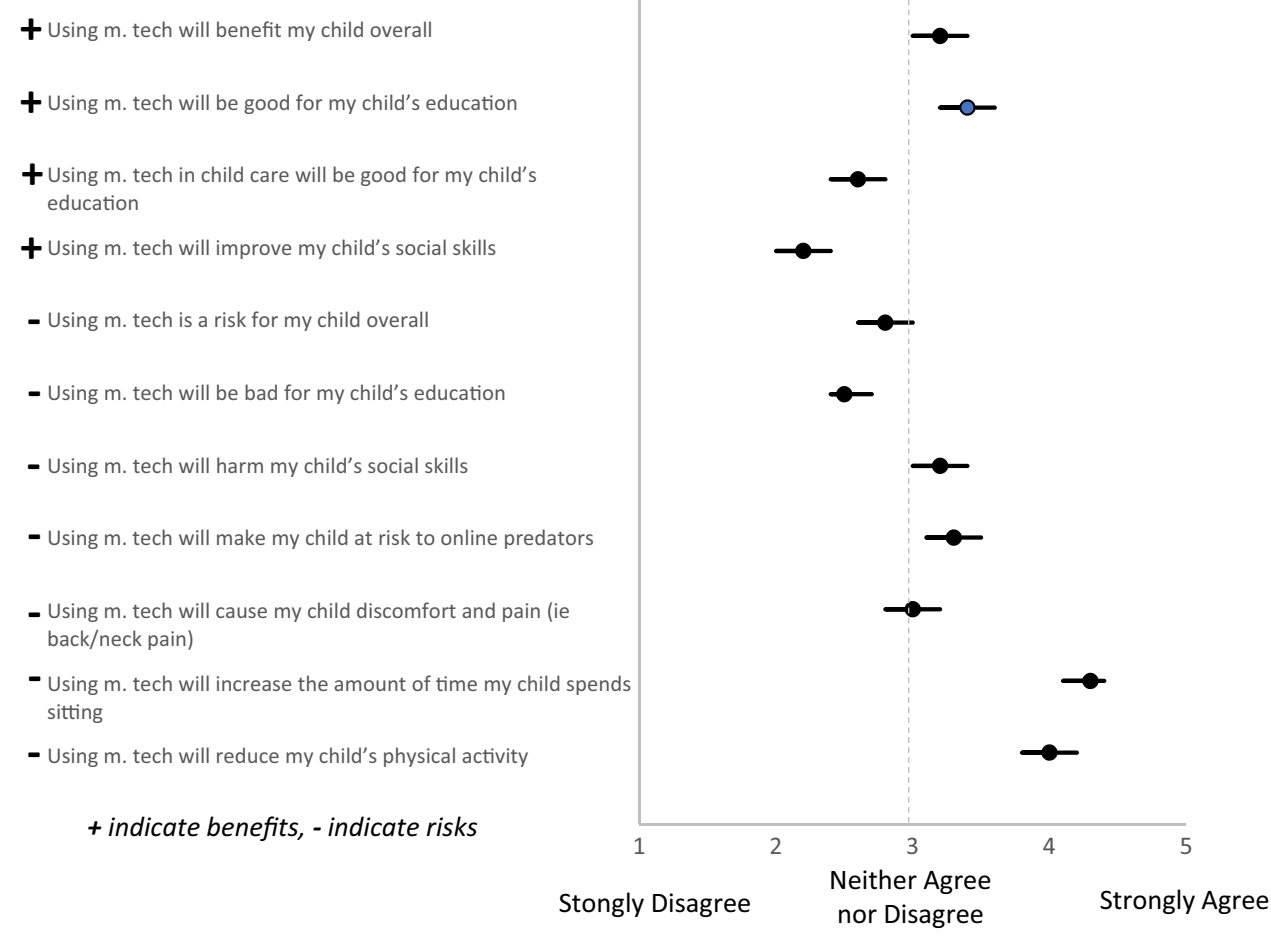

technology use (Solomon-Moore et al. 2018). Parents have knowledge of needing to limit screen use, and yet see the educational and practical benefits of it. Thus, there may be a need to reconcile current recommendations of strict limitations on screen use in young children with more practical advice of how to supervise "wise use". Similarly, as childcare settings are deciding whether or not to incorporate technology into their curriculums, they may encounter a range of parent opinions. Childcare providers must be aware of current practices and changing guidelines in order to decide how to intentionally incorporate technology and communicate to parents how technology can be used with children appropriately. Regardless, childcare settings are a key opportunity to influence parent attitudes and to teach children, and their families, about wise use of MTSDs, as parents may have limited prior experience with evolving technologies as a unique developmental phenomena (Yan 2018).

\section{Strengths and Limitations}

The current sample is not a representative sample and represented a higher socioeconomic status overall. Previous research suggests that the amount of technology use is similar across sociodemographic backgrounds, however the purpose and quality of use may differ (Harris et al. 2017). Large, representative samples that capture weekly duration, frequency, and purpose of use by device are needed to understand technology use across populations and identify groups who may be in most need of education and intervention to improve the quantity and quality of technology use to achieve better outcomes for children. As previously mentioned, while there are limitations of self- or proxyreported technology use, few alternatives exist as observation is labor intensive and technology tracking apps are limited to single devices.

\section{Practical Implications}

The current study provides for the utility of an instrument to assess technology use of young children and their parents. This may be useful for childcare providers to better understand family screen use contexts to inform areas for family education around screen use or technology skill instruction in children. Researchers can utilize the TechU-Q to further explore technology use, including monitoring changes in screen use over time, better understanding the context influences of screen use, determining the effects of various devices and purpose of use on child development, and ultimately evaluating interventions to modify screen use. It is important for both childcare practitioners and researchers to evaluate technology use within the family environment, as parent and child use are associated.

Whilst the data in this study were collected prior to the social disruptions associated with COVID-19, these changes emphasized the importance of understanding how to use technology wisely. Lockdowns enforced to reduce COVID19 transmission had implications for the physical, mental 
and social development of children. For example, physically active play opportunities were often reduced, education was often delivered through screen technologies, and children were often unable to visit their grandparents. The sudden reliance on MTSDs to support children in isolation exposed the limitations of guidelines that are time-based, and reinforced the need for more useful guidance about how to use these devices wisely.

\section{Conclusion}

Mobile touch screen device use is now a substantial exposure for many young children. Parents and professionals interested in child health, well-being and development need support on wise ways for young children to use this new generation of technology as they disentangle the complex techno-microsystem. The evidence to support such guidance requires reliable and valid assessments of child (and parent) technology use, by device and purpose, which the TechU-Q now provides. Future guidelines will be able to provide more informative and relevant advice to parents and professionals involved in childcare, health and development based on a better understanding of the nature of use and associated outcomes.

\section{Compliance with Ethical Standards}

Conflict of Interest The authors declare that they have no conflict of interest.

Publisher's note Springer Nature remains neutral with regard to jurisdictional claims in published maps and institutional affiliations.

\section{References}

Anderson, D. R., \& Subrahmanyam, K. (2017). Digital screen media and cognitive development. Pediatrics, 140, S57-S61. https://doi. org/10.1542/peds.2016-1758C.

Beyens, I., \& Nathanson, A. I. (2018). Electronic media use and sleep among preschoolers: evidence for time-shifted and less consolidated sleep. Health Communication, 1-8. https://doi.org/10. 1080/10410236.2017.1422102

Boulos, R., Vikre, E. K., Oppenheimer, S., Chang, H., \& Kanarek, R. B. (2012). ObesiTV: how television is influencing the obesity epidemic. Physiology \& Behavior, 107(1), 146-153. https://doi. org/10.1016/j.physbeh.2012.05.022.

Canadian Society for Exercise Physiology. (2017). Canadian 24-Hour Movement Guidelines for the Early Years ( $0-4$ Years): An Integration of Physical Activity, Sedentary Behaviour, and Sleep. https://www.participaction.com/sites/default/files/downloads/ PAR7972_24h_Guidelines_EY_En.pdf.

Carlson, D. S., Thompson, M. J., Crawford, W. S., Boswell, W. R., \& Whitten, D. (2017). Your job is messing with mine! The impact of mobile device use for work during family time on the spouse's work life. Journal of Occupational Health Psychology, 23, 471-482. https://doi.org/10.1037/ocp0000103.
Cherner, T., Dix, J., \& Lee, C. (2014). Cleaning up that mess: a framework for classifying educational apps. Contemporary Issues in Technology and Teacher Education, 14(2), 158-193.

Ciccarelli, M., Straker, L., Mathiassen, S. E., \& Pollock, C. (2011). ITKids part I: children's occupations and use of information and communication technologies. Work, 38(4), 401-412. https://doi. org/10.3233/wor-2011-1167.

Cleland, V., Crawford, D., Baur, L. A., Hume, C., Timperio, A., \& Salmon, J. (2008). A prospective examination of children's time spent outdoors, objectively measured physical activity and overweight. Int J Obes (Lond), 32(11), 1685-1693. https://doi. org/10.1038/ijo.2008.171.

Coenen, P., Howie, E., Campbell, A., \& Straker, L. (2015). Mobile touch screen device use among young Australian children-first results from a national survey. Paper presented at the Proceedings 19th Triennial Congress of the IEA, Melbourne, Australia.

Commonwealth of Australia. (2009). Belonging, being \& becoming: The early years learning framework for Australia. Retrieved from Canberra, ACT.

Council on Communications and Media American Academy of Pediatrics. (2016). Media and Young Minds. Pediatrics, 138, e20162591. https://doi.org/10.1542/peds.2016-2591.

Department of Health. (2017). Australian 24-Hour Movement Guidelines for the Early Years (birth to 5 Years): An Integration of Physical Activity, Sedentary Behaviour, and Sleep. http://www.health.gov.au/internet/main/publishing.nsf/content/ FCE78513DAC85E08CA257BF0001BAF95/\$File/Birthto5yea rs_24hrGuidelines_Brochure.pdf.

Domingo, M. G., \& Gargante, A. B. (2016). Exploring the use of educational technology in primary education: Teachers' perception of mobile technology learning impacts and applications' use in the classroom. Computers in Human Behavior, 56, 21-28.

Drumm, J., White, N., Chang, K., \& Huggins, K. (2017). Mobile Consumer Survey 2017: The Australian Cut. https://www2. deloitte.com/au/mobile-consumer-survey.

Harris, C., \& Straker, L. (2000). Survey of physical ergonomics issues associated with school children's use of laptop computers. International Journal of Industrial Ergonomics, 26(3), 337-347.

Harris, C., Straker, L., \& Pollock, C. (2017). A socioeconomic related 'digital divide' exists in how, not if, young people use computers. PLoS ONE, 12(3), e0175011. https://doi.org/10.1371/journal. pone. 0175011.

Hinkley, T., Brown, H., Carson, V., \& Teychenne, M. (2018). Cross sectional associations of screen time and outdoor play with social skills in preschool children. PLOS ONE, 13(4), e0193700. https:// doi.org/10.1371/journal.pone.0193700.

Hinkley, T., Salmon, J., Okely, A. D., Crawford, D., \& Hesketh, K. (2012). The HAPPY study: development and reliability of a parent survey to assess correlates of preschool children's physical activity. Journal of Science and Medicine in Sport, 15(5), 407-417. https://doi.org/10.1016/j.jsams.2011.12.009.

Hirsh-Pasek, K., Zosh, J. M., Golinkoff, R. M., Gray, J. H., Robb, M. B., \& Kaufman, J. (2015). Putting education in "educational" apps: lessons from the science of learning. Psychological Science in the Public Interest, 16(1), 3-34.

Houghton, S., Hunter, S. C., Rosenberg, M., Wood, L., Zadow, C., Martin, K., \& Shilton, T. (2015). Virtually impossible: limiting Australian children and adolescents daily screen based media use. BMC Public Health, 15, 5. https://doi.org/10.1186/1471-2458$15-5$.

Howard, J. (2017). Kids under 9 spend more than $2 \mathrm{~h}$ a day on screens, report shows. https://www.cnn.com/2017/10/19/health/childrensmartphone-tablet-use-report/index.html.

Howie, E. K., Coenen, P., Campbell, A. C., Ranelli, S., \& Straker, L. M. (2017). Head, trunk and arm posture amplitude and variation, muscle activity, sedentariness and physical activity of 3 to 
5 year-old children during tablet computer use compared to television watching and toy play. Applied Ergonomics, 65, 41-50. https://doi.org/10.1016/j.apergo.2017.05.011.

Johnson, G. (2010). Internet use and child development: the technomicrosystem. Australian Journal of Educational and Developmental Psychology (AJEDP), 10, 32-43.

Kabali, H. K., Irigoyen, M. M., Nunez-Davis, R., Budacki, J. G., Mohanty, S. H., Leister, K. P., \& Bonner, R. L. Jr. (2015). Exposure and use of mobile media devices by young children. Pediatrics, 136(6), 1044-1050. https://doi.org/10.1542/peds.2015-2151.

Klesges, R. C., Shelton, M. L., \& Klesges, L. M. (1993). Effects of television on metabolic rate: potential implications for childhood obesity. Pediatrics, 91(2), 281-286.

Koo, T. K., \& Li, M. Y. (2016). A guideline of selecting and reporting intraclass correlation coefficients for reliability research. J Chiropr Med, 15(2), 155-163. https://doi.org/10.1016/j.jcm.2016.02.012.

Kostyrka-Allchorne, K., Cooper, N. R., \& Simpson, A. (2017). Touchscreen generation: children's current media use, parental supervision methods and attitudes towards contemporary media. Acta Paediatr, 106(4), 654-662. https://doi.org/10.1111/apa.13707.

Lillard, A. S., Li, H., \& Boguszewski, K. (2015). Television and children's executive function. Advances in Child Develoment and Behavior, 48, 219-248. https://doi.org/10.1016/bs.acdb.2014.11.006.

Marinelli, M., Sunyer, J., Alvarez-Pedrerol, M., Iniguez, C., Torrent, M., Vioque, J., \& Julvez, J. (2014). Hours of television viewing and sleep duration in children: a multicenter birth cohort study. JAMA Pediatrics, 168(5), 458-464. https://doi.org/10.1001/jama pediatrics.2013.3861.

McCloskey, M., Johnson, S. L., Benz, C., Thompson, D. A., Chamberlin, B., Clark, L., \& Bellows, L. L. (2018). Parent perceptions of mobile device use among preschool-aged children in rural head start centers. Journal of Nutrition Education and Behavior, 50(1), 83-89.e81. https://doi.org/10.1016/j.jneb.2017.03.006.

Meinck, S., \& Rodriguez, M. C. (2013). Considerations for correlation analysis using clustered data: working with the teacher education and development study in mathematics (TEDS-M) and other international studies. Large-scale Assessments in Education, 1(1), 7. https://doi.org/10.1186/2196-0739-1-7.

Nathanson, A. I., \& Beyens, I. (2018). The relation between use of mobile electronic devices and bedtime resistance, sleep duration, and daytime sleepiness among preschoolers. Behavioral Sleep Medicine, 16(2), 202-219. https://doi.org/10.1080/15402002. 2016.1188389

Paciga, K. A., \& Donohue, C. (2017). Technology and Interactive Media for Young Children: A Whole Child Approach Connecting the Vision of Fred Rogers with Research and Practice. Latrobe, PA: http://teccenter.erikson.edu/wp-content/uploads/2017/06/FRCReport-2-1.pdf.

Pew Research Center. (2018). Mobile Fact Sheet. http://www.pew internet.org/fact-sheet/mobile/.

Polman, H., De Castro, B. O., \& van Aken, M. A. (2008). Experimental study of the differential effects of playing versus watching violent video games on children's aggressive behavior. Aggressive Behavior, 34(3), 256-264.

Przybylski, A. K., \& Weinstein, N. (2017). Digital screen time limits and young children's psychological well-being: evidence from a population-based study. Child Development. https://doi.org/10. 1111/cdev.13007.

Radesky, J. S., Peacock-Chambers, E., Zuckerman, B., \& Silverstein, M. (2016). Use of mobile technology to calm upset children: associations with social-emotional development. JAMA Pediatrics, 170(4), 397-399.

Radesky, J. S., Schumacher, J., \& Zuckerman, B. (2015). Mobile and interactive media use by young children: the good, the bad, and the unknown. Pediatrics, 135(1), 1-3. https://doi.org/10.1542/ peds.2014-2251.

Roseberry, S., Hirsh-Pasek, K., \& Golinkoff, R. M. (2014). Skype me! Socially contingent interactions help toddlers learn language. Child Development, 85(3), 956-970. https://doi.org/10.1111/cdev.12166.

Saunders, T. J., \& Vallance, J. K. (2017). Screen time and health indicators among children and youth: current evidence, limitations and future directions. Appl Health Econ Health Policy, 15 (3), 323-331. https://doi.org/10.1007/s40258-016-0289-3.

Skaug, S., Englund, K. T., Saksvik-Lehouillier, I., Lydersen, S., \& Wichstrom, L. (2017). Parent-child interactions during traditional and interactive media settings: A pilot randomized control study. Scandinavian Journal of Psychology. https://doi.org/10.1111/ sjop. 12420 .

Solomon-Moore, E., Matthews, J., Reid, T., Toumpakari, Z., Sebire, S. J., Thompson, J. L., \& Jago, R. (2018). Examining the challenges posed to parents by the contemporary screen environments of children: a qualitative investigation. BMC Pediatrics, 18(1), 129 https://doi.org/10.1186/s12887-018-1106-y.

Straker, L., Coleman, J., Skoss, R., Maslen, B., Burgess-Limerick, R., \& Pollock, C. (2008). A comparison of posture and muscle activity during tablet computer, desktop computer and paper use by young children. Ergonomics, 51(4), 540-555.

Straker, L., Harris, C., Joosten, J., \& Howie, E. K. (2017). Mobile technology dominates school children's IT use in an advantaged school community and is associated with musculoskeletal and visual symptoms. Ergonomics, 1-12. https://doi.org/10.1080/ 00140139.2017.1401671.

Straker, L., Zabatiero, J., Danby, S., Thorpe, K., \& Edwards, S. (2018). Conflicting guidelines on young children's screen time and use of digital technology create policy and practice dilemmas. Journal of Pediatrics, 202, 300-303. https://doi.org/10.1016/j. jpeds.2018.07.019.

Straker, L. M., Hall, G. L., Mountain, J., Howie, E. K., White, E., McArdle, N., \& Eastwood, P. R. (2015). Rationale, design and methods for the 22 year follow-up of the Western Australian Pregnancy Cohort (Raine) Study. BMC Public Health, 15, 663. https://doi.org/10.1186/s12889-015-1944-6.

Straker, L. M., \& Howie, E. K. (2016). Young children and screen time: It is time to consider healthy bodies as well as healthy minds. Journal of Developmental and Behavioral Pediatrics, 37 (3), 265. https://doi.org/10.1097/dbp.0000000000000265.

Toh, S. H., Coenen, P., Howie, E. K., \& Straker, L. M. (2017). The associations of mobile touch screen device use with musculoskeletal symptoms and exposures: a systematic review. PLOS ONE, 12 (8), e0181220. https://doi.org/10.1371/journal.pone.0181220.

Vernon, L., Modecki, K. L., \& Barber, B. L. (2018). Mobile phones in the bedroom: Trajectories of sleep habits and subsequent adolescent psychosocial development. Child Development, 89(1), 66-77. https://doi.org/10.1111/cdev.12836.

Waisman, I., Hidalgo, E., \& Rossi, M. L. (2018). Screen use among young children in a city of Argentina. Archivoes Argentinos de Pediatria, 116(2), e186-e195. https://doi.org/10.5546/aap.2018. eng.e186.

Yadav, S., \& Chakraborty, P. (2017). Children aged two to four are able to scribble and draw using a smartphone app. Acta Paediatrica, 106(6), 991-994. https://doi.org/10.1111/apa.13818.

Yan, Z. (2018). Child and adolescent use of mobile phones: An unparalleled complex developmental phenomenon. Child Development, 89(1), 5-16. https://doi.org/10.1111/cdev.12821.

Zabatiero, J., Amantilla, A., Edwards, S., Danby, S., \& Straker, L. (2018). Young children and digital technology: Australian early childhood education and care sector adults' perspectives. Australasian Journal of Early Childhood, 43(2), 14-22. 